\title{
Using 2D inversion of magnetic resonance soundings to locate a water-filled
}

karst conduit

M. Boucher ${ }^{1,5}$, J.-F. Girard ${ }^{1}$, A. Legchenko ${ }^{2}$, J.-M. Baltassat ${ }^{1}$, N. Dörfliger ${ }^{3}$, K. Chalikakis $^{4}$

${ }^{1}$ BRGM, 3 Avenue C. Guillemin, BP 6009, Orléans Cedex, France. E-mail: jf.girard@brgm.fr

${ }^{2}$ LTHE, BP 53, 38041 Grenoble Cedex 9, France.

E-mail anatoli.legtchenko@hmg.inpg.fr

${ }^{3}$ BRGM, 1039 Rue de Pinville, 34000 Montpellier, France. E-mail: n.dorfliger@brgm.fr

${ }^{4}$ Université Pierre et Marie Curie (Paris 6), UMR 7619 SISYPHE, Case 105, 4 Place Jussieu, 75252 Paris Cedex 05, France

${ }^{5}$ ISTO, UMR6113 CNRS/Université d'Orléans, Bâtiment Géosciences, Rue de Saint Amand, BP 6759, 45067 Orléans Cedex 2, France

\section{Abstract}

A new methodology for Magnetic Resonance Sounding (MRS) data acquisition and interpretation was developed for locating water-filled karst cavities. This methodology was used to investigate the Ouysse karst system in the Poumeyssens shaft in the Causse de Gramat (France). A new 2D numerical MRS response model was designed for improved accuracy over the previous 1D MRS approach. A special survey performed by cave divers confirmed the accuracy of the MRS results. Field 
results demonstrated that in favourable conditions (a low EM noise environment and a relatively shallow, large target) the MRS method, used with a coincident transmitter/receiver loop, can be an effective tool for locating a water-filled karst conduit. It was shown numerically that because an a priori orientation of the MRS profile with the karst conduit is used in the inversion scheme (perpendicular for instance), any error in this assumption introduces an additional error in locating the karst. However, the resulting error is within acceptable limits when the deviation is less than $30^{\circ}$. The MRS results were compared with an Electrical Resistivity Tomography (ERT) survey. It was found that in Poumeyssens, ERT is not able to locate the water-filled karst. On the other hand, ERT provides additional information about heterogeneities in the limestone.

Keywords: geophysical methods, karst, Causse de Gramat, MRS

\section{Introduction}

A karst aquifer is a specific environment composed of a karst conduit network within a fissured rock matrix and is characterised by very heterogeneous hydraulic parameters. The karst network governs hydraulic transmissivity and the fissured rock governs the storage function in the karst aquifer. Each karst system is unique, and the geometry of its conduits can be rather complex. Conduits can develop at various levels and extend from a few kilometres to a hundred kilometres. Karst conduits may be filled with water or not, depending on their position within the aquifer.

Karst aquifers are generally tapped at their springs. However, it can be inconvenient to collect water at the surface from karst springs. Thus, active water management 
may necessitate pumping of water through boreholes. In order to drill a borehole in the area of a spring, one must know the exact position of the karst conduit within the saturated zone of the aquifer. Water-filled karst conduits can be located either by underground topographical survey, if there is access for cave divers, or by using surface geophysical survey methods such as micro-gravity, seismic, georadar, electric and electromagnetic methods (Beres et al., 2001; Al-fares et al., 2002; Šumanovac et al., 2001; Doolittlle et al., 1998).

Magnetic Resonance Sounding (MRS) is one of the most recent surface geophysical methods developed for groundwater investigation and its utility in locating water-filled karst cavities has recently been demonstrated (Vouillamoz et al., 2003). In this paper we present a methodology for the acquisition and interpretation of MRS data from soundings performed above a known karst system at Poumeyssens in the Causse de Gramat (Lot Department, SW France). A new 2D numerical MRS response model (Girard et al., 2005) was applied for greater accuracy in locating karst conduits as compared with the 1D MRS approach previously used.

\section{The Ouysse karst network}

The Poumeyssens test site is located in the Lot Department of France. It is in the immediate vicinity of the Poumeyssens karst shaft from which it takes its name, as shown in Figure 1. This vertical shaft, situated about 700 metres upstream of the Cabouy spring provides access to a major conduit connected to one of the main outlets of the Ouysse karst system. The site was chosen for its favourable conditions: the location of the karst conduit is well known; it is a large, shallow, probably single conduit and is full of water at all seasons. It should be mentioned that the MRS method cannot be applied in urban areas because it is sensitive to the 
electromagnetic noise generated by human activities (such as power lines). Located far from any source of electromagnetic noise, this test site has the advantage of a relatively low noise level.

\section{Geology}

The Ouysse karst network is located in the Causse de Gramat (a unit of the Quercy Causses), in the NE part of the Aquitaine sedimentary basin. The Gramat Causse is bounded by the Lot River to the south and the Dordogne River to the north. It is made up of Middle and Upper Jurassic limestone overlaying the Lias marls.

The system's outlets and the vertical Poumeyssens shaft developed within the lower Callovian limestone (Rocamadour formation, Carberets member). This is a homogeneous unit of fine micrite limestone in beds a metre thick. The maximal thickness of the formation is about 50 metres (Astruc et al., 1994).

All these layers lie on impervious sandstone (Lower Hettangian and Trias) and on the Ségala crystallophyllites (Palaeozoic) on the western boundary of the Massif Central (Beaudoing et al., 1989).

\section{Hydrology}

The Ouysse system is an allogenic karst system, i.e. recharge occurs both by precipitation and by river infiltration at swallow holes such as Thémines and Théminettes. The outlet of the system consists of three major springs: the Cabouy, Fontbelle and St-Sauveur springs (Figure 1). According to previous studies (Beaudoing et al., 1989; Dzikowski et al.,1995), the boundaries of the system's catchment area were determined based on the geological context, groundwater flow directions and the hydraulic connections shown by artificial tracing tests. The total 
catchment basin includes an area of $540 \mathrm{~km}^{2}$, of which $360 \mathrm{~km}^{2}$ lies within the Gramat Causse. Several cavities allow direct access to the underground karst network, which is more than $14 \mathrm{~km}$ long.

The Poumeyssens vertical shaft is a collapse zone due to a succession of faults oriented perpendicularly to the dry valley (Touloumidjian, 1977). During the high water season, surface runoff is absorbed by the shaft and during peak flow of the Ouysse, this point may act as a temporary discharge point.

\section{Locating the karst conduit with cave divers}

The karst network of the Ouysse system is accessible to cave divers. Part of the conduit was previously mapped in order to drill a borehole at the Cabouy spring (Muet, 2002) and during previous speleological explorations (Figure 1). The part of the conduit downstream from the Poumeyssens swallow hole was mapped after geophysical investigations were completed.

The 150-metre-long survey was performed using a compass and a graduated Ariane's diveline. During mapping, the visibility was about 3 metres. Divers followed the right bank on the way out and the left bank on the way back in order to map the section of conduit. The accuracy of this method was determined when the divers came back to the starting point: in this case, a total error of 10 metres was observed in the measurement loop.

In order to reduce this uncertainty, electromagnetic beacons were installed inside the conduit and then located from the surface by triangulation. The margin of error in locating beacons was estimated at $\pm 50 \mathrm{~cm}$, which is considered acceptable. One of the beacons was installed close to the intersection with the geophysical survey in 
order to ensure that precision would be better than $1 \mathrm{~m}$ at the MRS profile intersection.

In addition, cave divers measured cross-section geometry at three specific locations. The map and sections obtained are presented in Figure 2. It can be seen that the conduit is relatively rectilinear and the base level is at a relatively constant elevation of about 92 metres (16 metres below the water level in the shaft) while the crosssection changes rapidly.

\section{Electrical Resistivity Tomography (ERT)}

In conjunction with the MRS investigation, a 155-metre-long Electrical Resistivity Tomography (ERT) profile was performed in order 1) to define the underground conductivity distribution below the test site, a necessary step for MRS modelling (Legchenko et al., 1997), 2) to give some indication of the homogeneity of the limestone massif and 3) to test the electrical response of a well defined water-filled gallery of this type. The total length of the profile was limited to 155 metres due to the valley's steep slopes and a Wenner-Shlumberger array with 5-metres electrode spacing was used.

Inversion of ERT data is shown in Figure 3. Several inversion varying regularization parameters were performed but did not drastically alter the result. It was found that the ground is highly resistive (mostly $>5000 \Omega . \mathrm{m}$ ), but a low-resistivity anomaly between x-coordinates $75 \mathrm{~m}$ and $85 \mathrm{~m}$ can be clearly seen. The groundwater in the Poumeyssens swallow hole is conductive ( $20 \Omega$.m or $500 \mu \mathrm{S} / \mathrm{cm}$ ) if compared to the limestone. Therefore, the electrical anomaly could be interpreted either as a signature of the karst conduit positionor as a fractured zone filled with clay. 
A comparison of the ERT anomaly with the location of the cavity as determined by cave divers suggests that the observed conductive anomaly is more likely due to a fractured zone than to the cavity itself.

\section{MRS results}

\section{MRS signatures of a karst aquifer}

MRS is an active, non-invasive geophysical tool that provides information on the physical properties of water-saturated rocks and it is specifically used for groundwater investigation. The measured signal is directly related to the volume of groundwater (, and its relaxation time is correlated with the size of the water-filled pores (Legchenko et al., 2004 and Kenyon, 1997). Inversion of MRS data reveals a vertical distribution of the water content and of the relaxation time in the subsurface. The maximum depth of investigation with MRS is about $100 \mathrm{~m}$.

A karst aquifer may be represented schematically as a water-saturated limestone matrix with a water-filled cavity. In terms of the MRS method, the matrix is characterized by low water content (approximately 1\%) and relatively short relaxation times (100-150 ms). MRS reveals a strong contrast between the water-filled cavity and the matrix, as shown in Figure 4. The cavity shows much higher water content as well as a longer relaxation time. The signal measured by MRS is composed of the sum of the signals from the limestone matrix and from the water in cavities. The detectability of a karst conduit typically depends on its volume and its depth: for any given depth, the greater the volume of the cavity, the greater the difference between the karst MRS response and those of the surrounding environment. This contrast makes it possible to reliably identify the water-filled cavities (Vouillamoz et al., 2003). 


\section{Field setup}

Two MRS surveys, each composed of several soundings aligned along profiles, were undertaken in November 2003 and July 2004. The NUMIS ${ }^{\text {plus }}$ Magnetic Resonance Sounding system developed by IRIS Instruments was used.

In 2003, the karst conduit was reliably detected and these preliminary results provided encouragement for a more comprehensive study at this site. In order to improve the signal-to-noise ratio, a two-turn figure-eight square loop (19 m wide) was used (Trushkin et al., 1994).

In 2004, a single three-turn square loop (25 m wide) was used. This loop improved the lateral resolution when compared with the figure-eight loop setup. This is because, with MRS, the volume being investigated corresponds roughly to a cylinder whose diameter depends on the loop size. Thus, the larger figure-eight loop integrates a larger area than a single square and lateral resolution is reduced.

In order to improve the signal-to-noise ratio, a compensation square loop was connected to the measuring loop in such a way that induced noise currents went in opposite directions in each loop, as shown in Figure 5. This connection is similar to the figure-eight loop. In order to measure only the noise, the compensation loop was set far enough from the transmitting loop so that it did not receive the MRS signal. Such a setup has the advantages of both the square and figure-eight loops. The results of two soundings taken in exactly the same place and with the same acquisition parameters show (Figure 5) that the compensation loop can reduce recorded noise twice if compared to a single square loop.

Since the relaxation time of the signal from free water in the karst cavity was expected to be long, the signal recording time was increased from the usual value of 
$240 \mathrm{~ms}$ to $310 \mathrm{~ms}$. In order to increase the stability of current pulses generated by the NUMIS system, the pulse duration was set at $20 \mathrm{~ms}$ instead of the usual $40 \mathrm{~ms}$.

\section{D MRS interpretation}

During the previous study of a karst aquifer using the MRS method (Vouillamoz et al., 2003), each sounding was inverted independently, assuming a horizontally stratified subsurface (1D inversion). Then the results of the inversion were interpolated along the MRS profile. The location of the conduit was identified by calculating the product of water content and relaxation time (Vouillamoz et al., 2003). However, it is known that some additional errors, such as overestimation of the conduit section or biased localisation (Girard et al., 2005), should be expected when using a 1D model for data inversion above a $2 \mathrm{D}$ target. In order to improve the lateral resolution, a 2D MRS modelling program was developed. This new program was applied to the Poumeyssens karst investigation.

The MRS profile was taken moving the loop by steps. The results presented in Figure 6 reveal a smooth variation in amplitude. In Figure 7, MRS results obtained right above the cavity (station ROC11a) are compared with MRS results from the distant location not influenced by the cavity (station ROC12). As it was expected, both the MRS amplitude and the relaxation time were higher above the karst cavity. It can be assumed that the MRS response measured at station ROC12 outside the anomaly corresponds to the part of the MRS signal generated solely by water in the limestone matrix, and that the signal measured at station ROC11a was generated by water both in the matrix and in the cavity. This assumption will be used in the inversion process. 
Numerical modelling results show that in 1D MRS interpretation, layered aquifers that have equal water volumes (the product of thickness times water content) are equivalent when situated at the same depth (Legchenko and Shushakov, 1998). Because of this equivalence, the MRS response from a water-filled conduit with a cross-section smaller than the MRS loop diameter is not influenced by the shape of the cavity, but only by its volume and its depth, as shown in Figure 8 (Girard et al., 2005). Consequently, in the $2 \mathrm{D}$ inversion scheme used here, the conduit is simplified, using an elongated parallelepiped perpendicular to the MRS profile. An inversion of the data set yields an estimate of its cross-section, its depth and its horizontal position.

In both $1 \mathrm{D}$ and $2 \mathrm{D}$ cases, the depth of investigation is directly related to the pulse intensity and is a function of the electrical conductivity of the ground, the size of the loop and the local geomagnetic field. Consequently, even for a 2D structure like this, a $1 \mathrm{D}$ inversion of a sounding located at the anomaly apex can be used to estimate the depth of the karst conduit. Modelling shows that the MRS anomaly produced by a karst conduit always presents a flat maximum. In Figure 9A, MRS amplitudes are plotted for each pulse and each station. One can observe that MRS signals measured at three neighbouring stations over the target (ROC17, ROC11a, ROC13) have a maximum amplitude for nearly the same pulse intensity. Any of these three soundings can therefore be used to estimate the depth of the middle of the karst conduit, which was calculated at 17 metres below the topographical surface.

Having obtained the depth, the remaining parameters (the cross-section and the position) were calculated by applying an iterative algorithm. As shown in Figure 9B, exploration of the two parameters solutions space $(x, S)$ shows only one minimum for the objective function (RMS). This optimization process, thus yields an estimation of 
the cross-section and the position of the cavity. Inversion results show that the best model has a $42 \mathrm{~m}^{2}$ cross-section, located at x-coordinate $67 \mathrm{~m}$. For each station, the measured data and the calculated signal of this model are plotted in Figure 9A. The MRS inversion results are consistent with the position of the cavity as measured by speleological investigation (Figure 9C). Lastly, the depth to the middle of the gallery was determined with an error of $2 \mathrm{~m}$, the location of the gallery centre on the $\mathrm{x}$-axis with an error of less than $1 \mathrm{~m}$ and the cross-section contained within the range of the sections (40-45 $\left.\mathrm{m}^{2}\right)$ that were measured during the diver survey.

\section{Discussion}

In the 2D inversion, the karst conduit is assumed to be perpendicular to the MRS profile. For practical purposes, it is important to investigate whether MRS results change when the MRS profile deviates from being perpendicular to the karst conduit. The responses of an east-west- and a north-south-oriented karst conduit, $17 \mathrm{~m}$ deep and $40 \mathrm{~m}^{2}$ in cross-section, were calculated for MRS profiles taken from different orientations. Then the data sets were inverted assuming a conduit perpendicular to the MRS.

Inversion results are presented in Figure 10. One can see that if the MRS profile is not perpendicular to the karst conduit, then the target appears larger and it has been shifted from its actual position. When the profile direction deviates less than $30^{\circ}$ azimuth from perpendicular to the karst conduit, the error is not dramatic considering the width of the conduit (less than $1.5 \mathrm{~m}$ for the position and less than $4 \mathrm{~m}^{2}$ for the cross-section). As a general rule, when solid assumption on the azimuth between the MRS profile and the karst conduit is known, even within a $30^{\circ}$ error, it has to be used 
to improve the inversion result. In any case, the best orientation of the MRS profile is perpendicularly to the conduit.

\section{Conclusion}

Field investigations of the Poumeyssens karst system confirm that in favourable conditions (a low EM-noise environment and a relatively shallow, large target) the MRS method used with a coincident transmitter/receiver loop can be an effective tool for locating a water-filled karst conduit. MRS results are consistent with the information obtained by a cave diving survey.

It was demonstrated that when the MRS profile deviates from perpendicular to the karst drain, this produces an additional error in locating the karst unless the deviation is taken into account in the model. However the resulting error is acceptable if the deviation is less than $30^{\circ}$.

An Electrical Resistivity Tomography (ERT) was performed in order to provide the electrical conductivity model for MRS processing. It was found that in the Poumeyssens site ERT is not able to locate the water-filled karst, but ERT gives additional information about heterogeneities in the limestone.

\section{Acknowledgements}

The authors would like to thank M. Bakalowicz and V. Plagnes for visiting and commenting on the test site, the DDAF Lot for their interest in MRS investigation methods for karst hydrogeology, Mr. A. Lavaux, the owner of the test site; and the SOLEN company and their client company, SIAEP Cave-Rocamadour, who allowed us to publish the map of the conduit upstream of Cabouy. 
This study was carried out as part of BRGM's research projects in 2004, KARSTEAU and HYCAR (PNRH).

\section{References:}

Al-fares W., Bakalowicz M., Guérin R. and Dukhan M. (2002), Analysis of the karst aquifer structure of the Lamalou area (Hérault, France) with ground penetrating radar. Journal of Applied Geophysics, 51:97-106.

Astruc J.-G., Coustou J.-C., Cubaynes R., Galharague J., Lorblanchet M., Marcouly R., Pélissié T. and Rey J. (1994), Notice explicative, Carte géol. France (1:50,000), Gramat sheet (833). Orléans: BRGM, 69p. Geologic map by J.G. Astruc (1994).

Beaudoing G., Astruc J.-G., Baradat J.-M., Bouziges M., Charentus T., Coustou J.C., Getto D., Mouyon P., Ricard J., Sauty J.-P., Tarrisse A. and Vicente A. (1989), Traçages et protection des captages dans le karst : détermination des paramètres de transfert et prévision de la propagation des pollutions dans le réseau karstique de l'Ouysse Causse de Gramat (Lot, France) [Tracing and protection of water catchments in karst; determining transport parameters and predicting the propagation of pollutants in karst networks of Ouysse, Gramat karst plateau, Lot, France]. Hydrogéologie, 4:279-292.

Beres M., Luetscher M. and Raymond O. (2001), Integration of penetrating radar and microgravimetric methods to map shallow caves. Journal of Applied Geophysics, 46:249-262.

Doolittle J. and Collins M. (1998), A comparison of EM induction and GRP methods in areas of karst. Geoderma, 85:83-102. 
Dzikowski M., Delay F., Sauty J.-P., Crampon N., and de Marsily G. (1995), Convolution in time-dependent system from artificial tracer test responses; application on a karst system (Causse de Gramat, Lot, France). Journal of Hydrology, 164(1-4):305-324.

Girard J.-F., Boucher M., Legchenko A., Baltassat J.-M. (2005), Numerical Modeling of Magnetic Resonance Signal from Water-Filled Cavities. Proceedings, EAGE Near Surface Geoscience Division, Palermo, Italy, 4-7 September 2005. paper B037, CD ROM edition.

Kenyon W. E. (1997), Petrophysical principles of applications of NMR logging. The Log Analyst, March-April 1997: 21-43.

Legchenko A., Beauce A., Guillen A., Valla P. and Bernard J. (1997), Natural variations in the magnetic resonance signal used in PMR groundwater prospecting from the surface. European Journal of Environmental Engineering Geophysics, 2:173-190.

Legchenko A. V. and Shushakov O. A. (1998), Inversion of surface NMR data. Geophysics, 63(1):75-84.

Legchenko A., Baltassat J.-M., Bobachev A., Martin C., Robain H., Vouillamoz J.-M. (2004), Magnetic resonance sounding applied to aquifer characterization. Ground Water, 42(3):363-373.

Muet P. (2002), Source de Cabouy. Implantation d'un forage pour captage des eaux souterraines. [Cabouy spring. Installation of a borehole for groundwater capture.] Rapport SOLEN egs.

Šumanovac F., Weisser M. (2001), Evaluation of resistivity and seismic methods for hydrological mapping in karst terrains. Journal of Applied Geophysics, 47: 13-28. 
Touloumidjian C. (1977), 7 trous en France [7 holes in France]. Etudes et sports sous-marins, 37:13-17.

Trushkin D. V., Shushakov O. A., Legchenko A. V. (1994), The potential of noisereducing antenna for surface NMR groundwater surveys in the earth's magnetic field. Geophysical Prospecting, 42:855-862.

Vouillamoz J.-M., Legchenko A., Albouy Y., Bakalowicz M., Baltassat J.-M. and AlFares W. (2003), Localization of karst aquifer with magnetic resonance sounding and resistivity imagery. Journal of Ground Water, 41(5):578-587. 


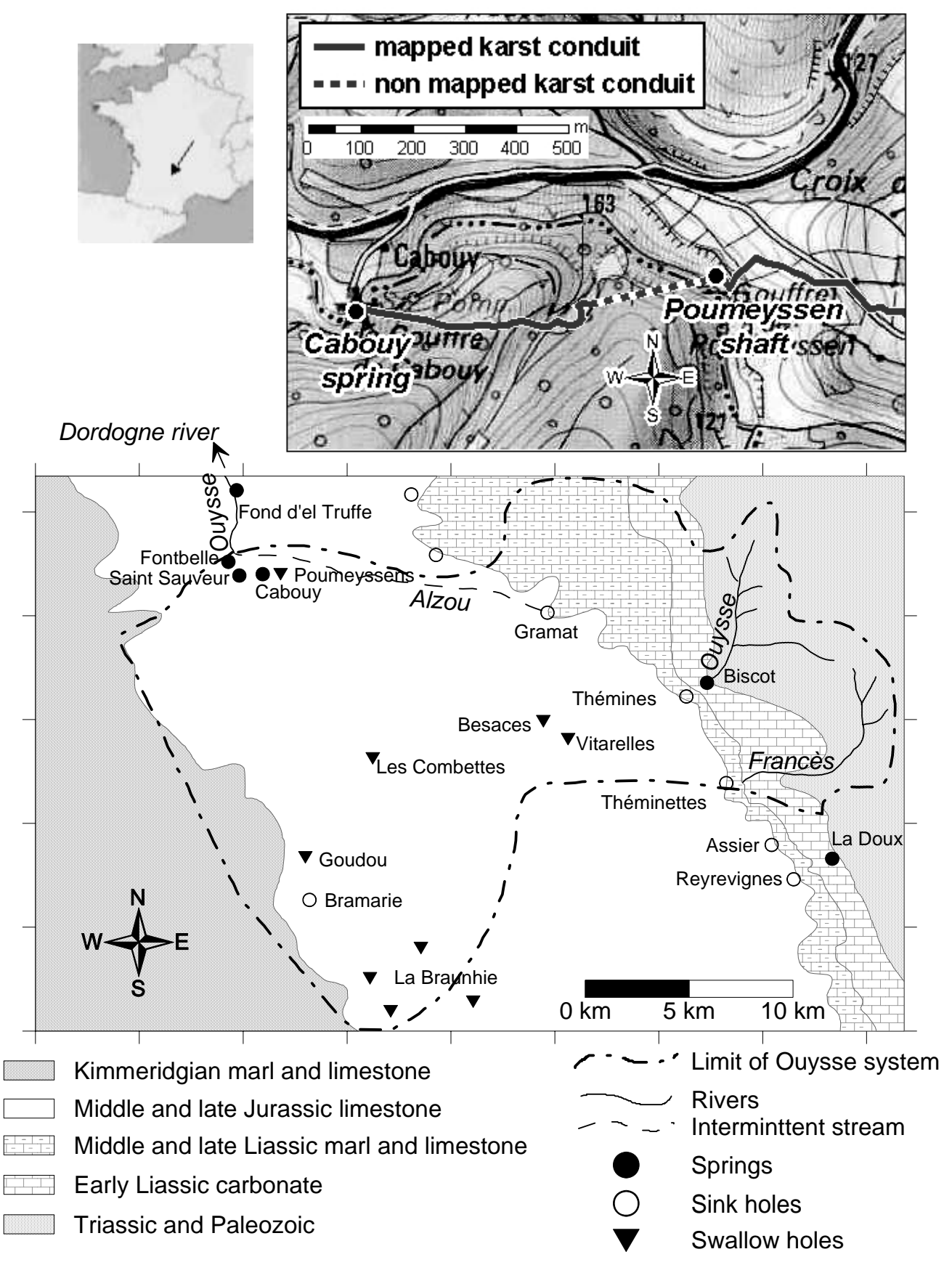

Figure 1: Geographical location and geological setting of the Ouysse karst system (Astruc et al., 1994). 

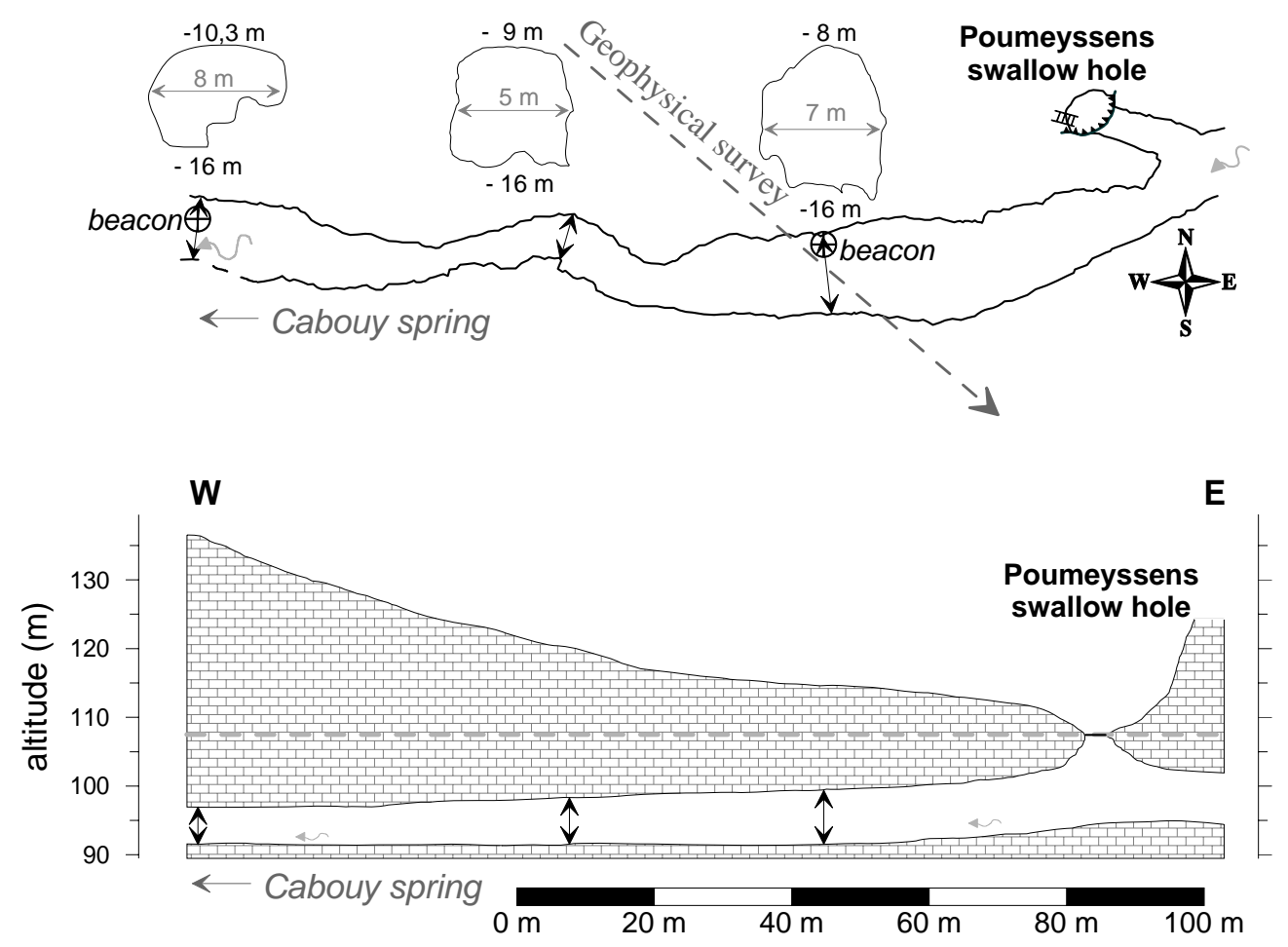

Figure 2: Map of the Poumeyssens karst conduit as measured by cave divers. 


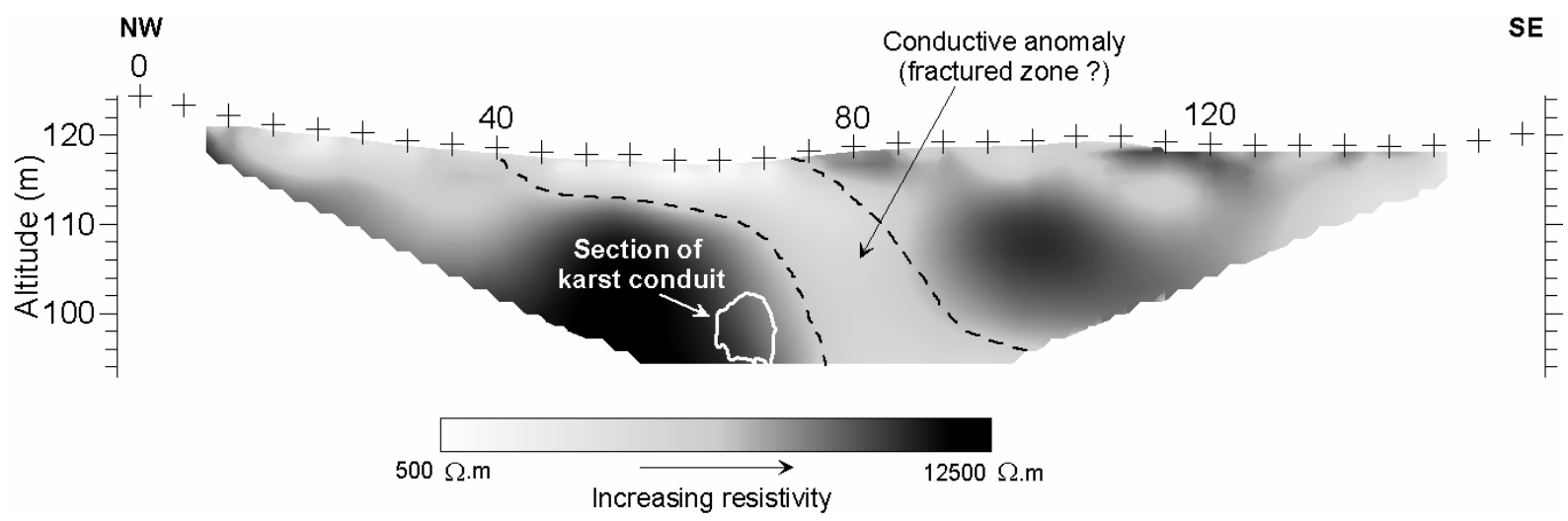

Figure 3: Electrical resistivity cross-section in the Poumeyssens area. 


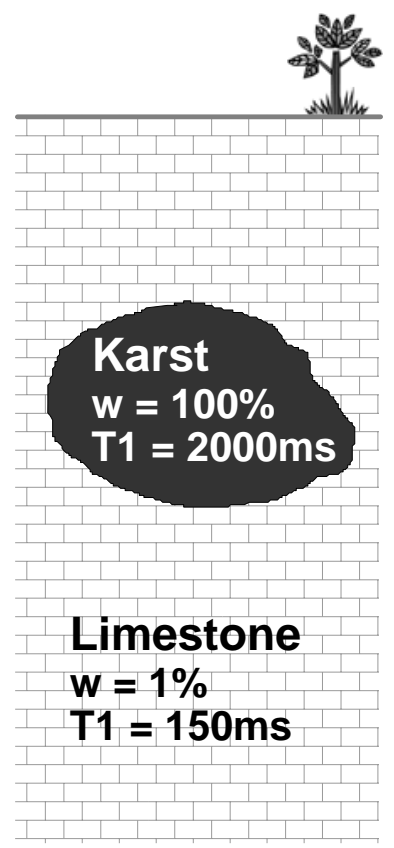

Figure 4: MRS signatures of a karst aquifer. 
Single loop

4
Measuring

loop

4

$r$

- Emission

- Reception
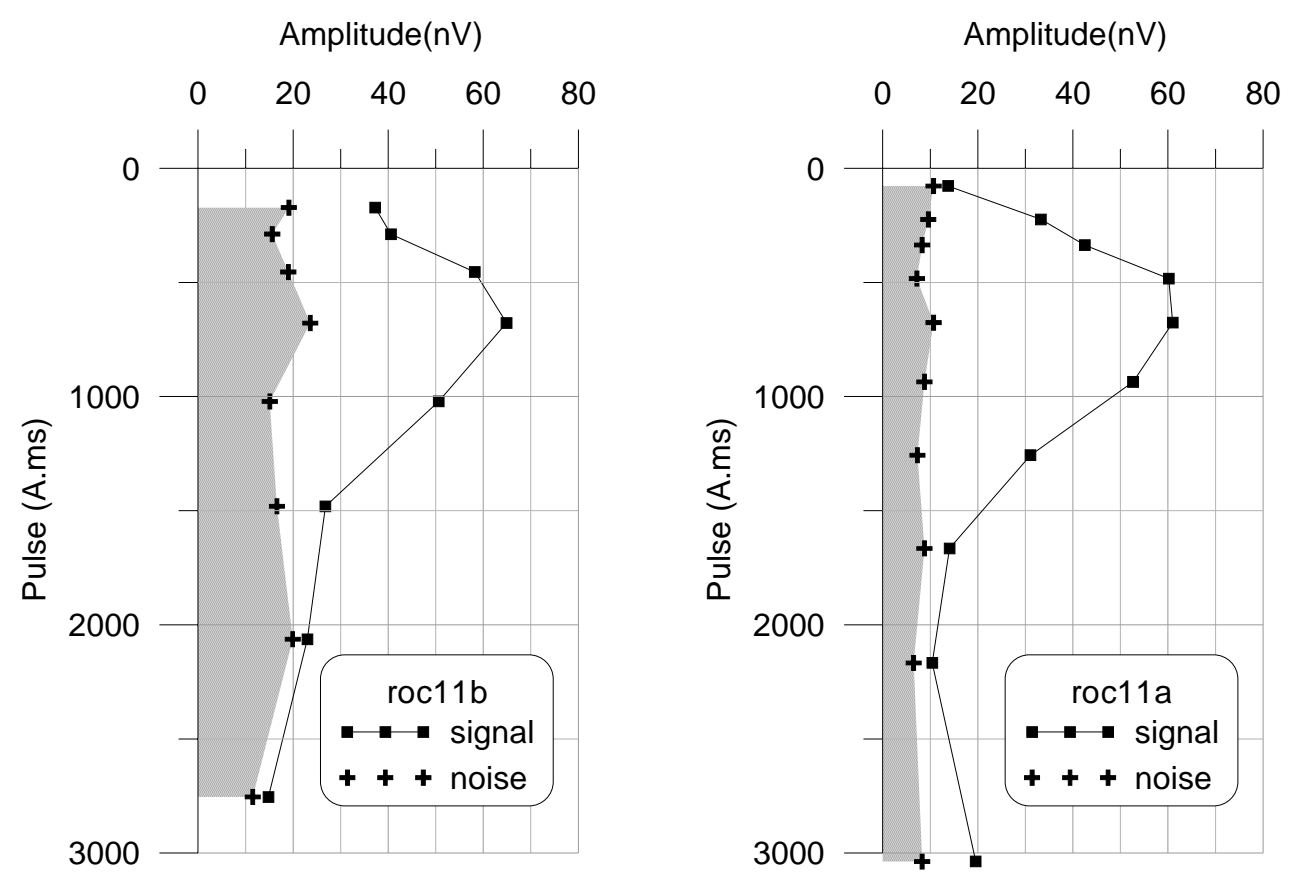

Figure 5: MRS signal and noise recorded using a single loop (left panel) versus a measuring loop in conjunction with a compensation loop (right panel). 


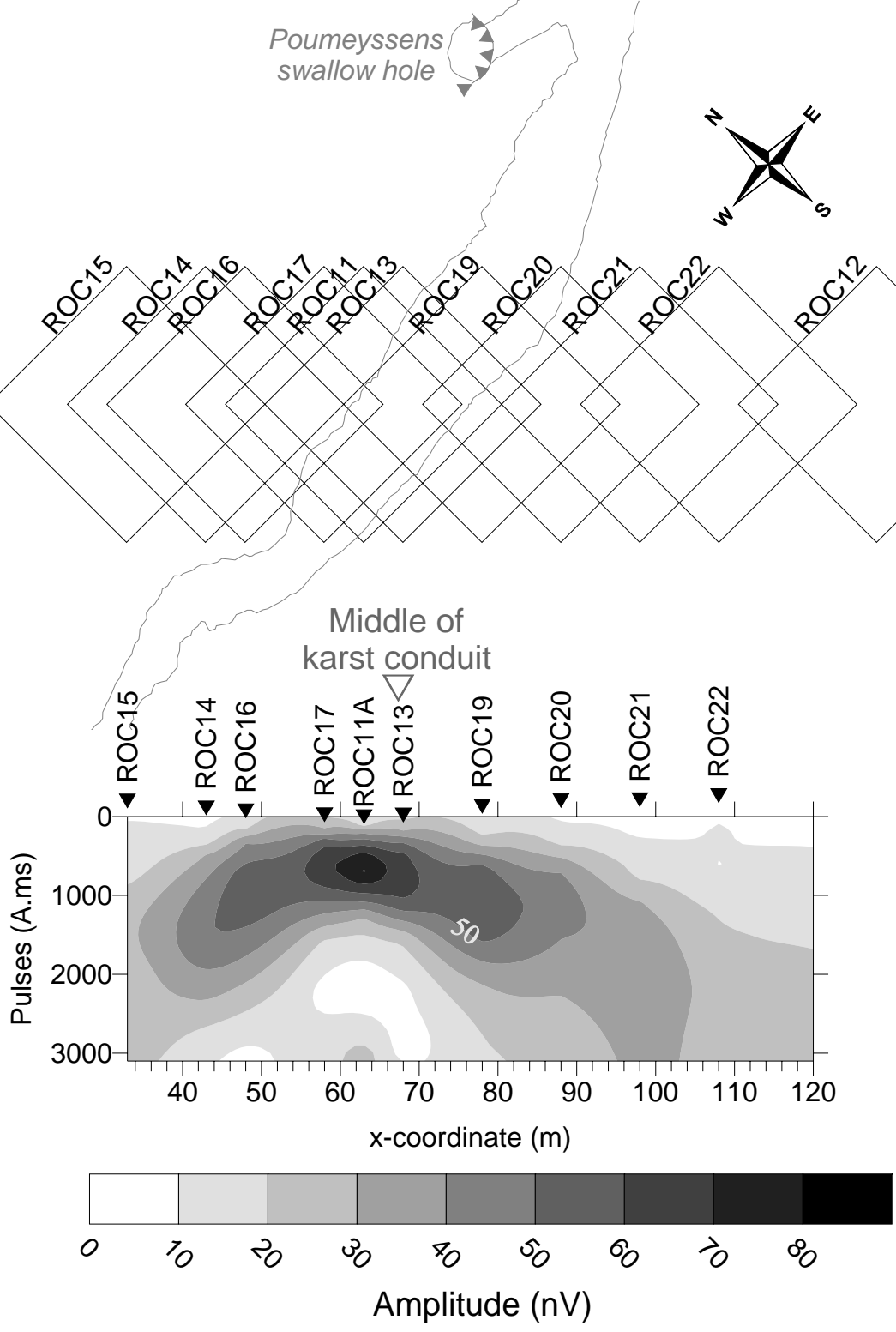

Figure 6: MRS amplitude cross-section in the Poumeyssens test site. 

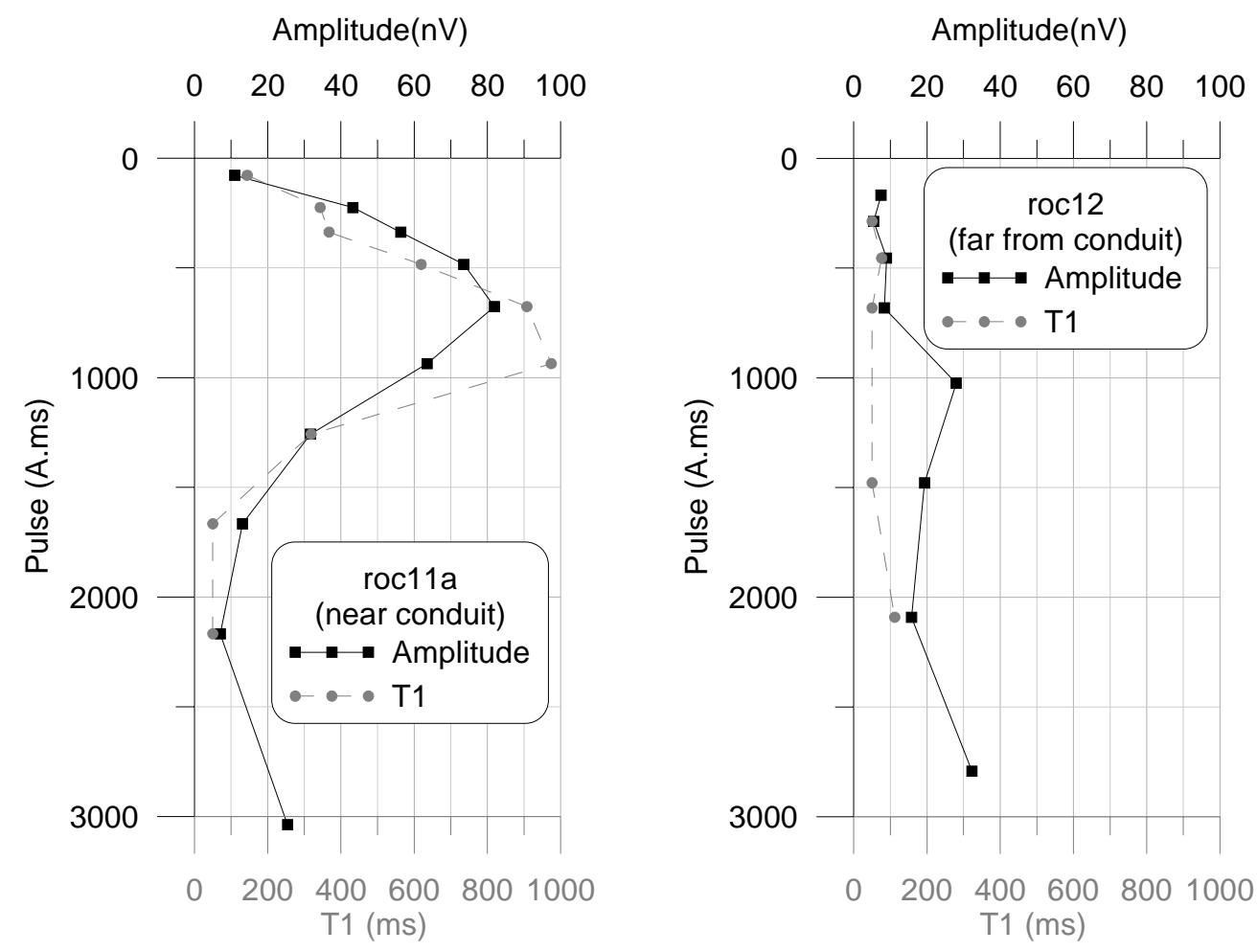

Figure 7: Example of soundings taken near to (left panel) and far away (right panel) from the karst cavity location. 


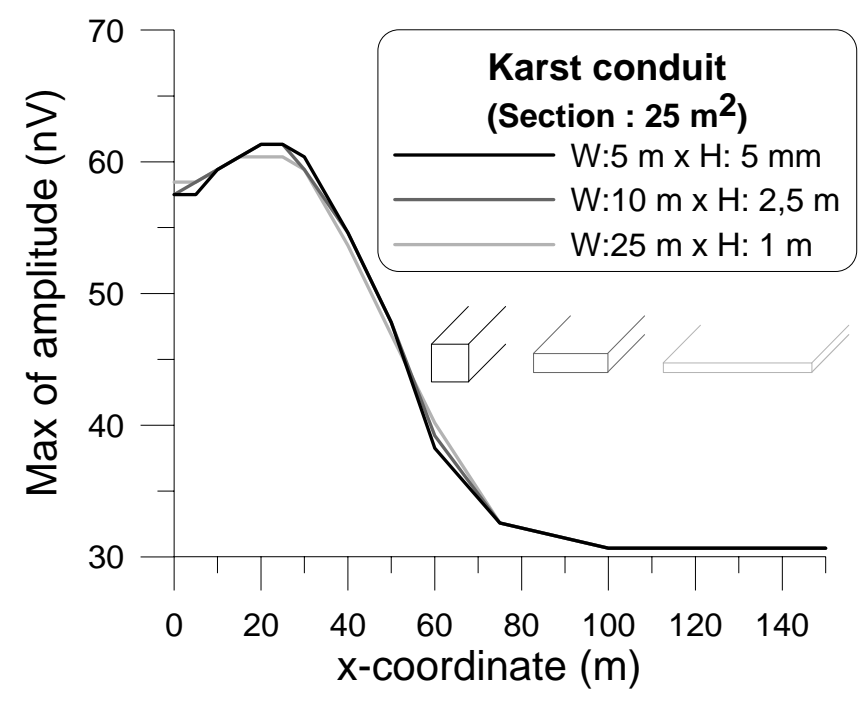

Figure 8: Influence of the karst conduit's shape on the MRS signal. 


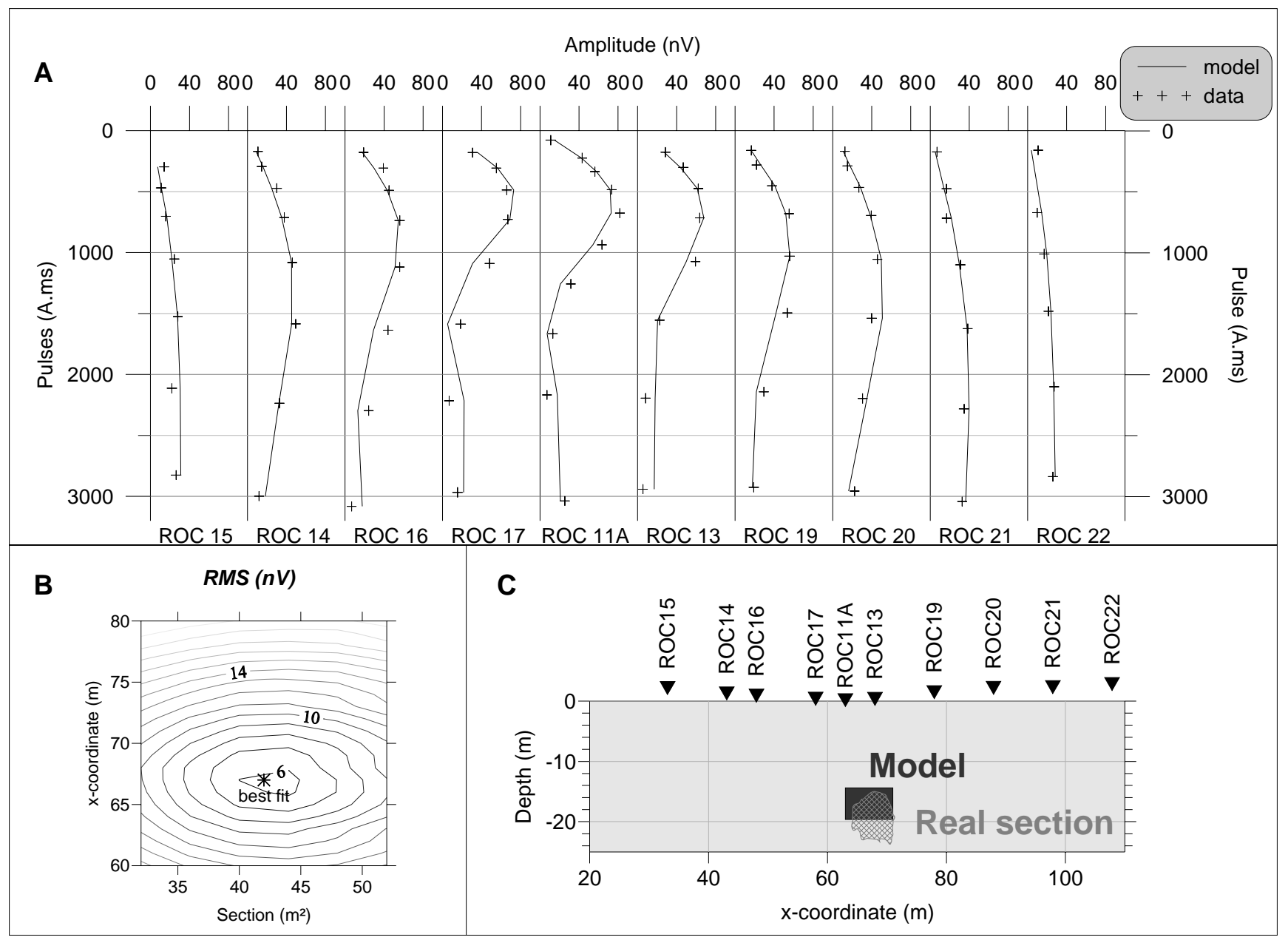

Figure 9: 2D Inversion. A: measured (plus signs) and theoretical signals along the MRS profile - B: RMS as a function of the cavity location and cross-section - C: Result of MRS inversion compared to the section drawn by speleologists. 

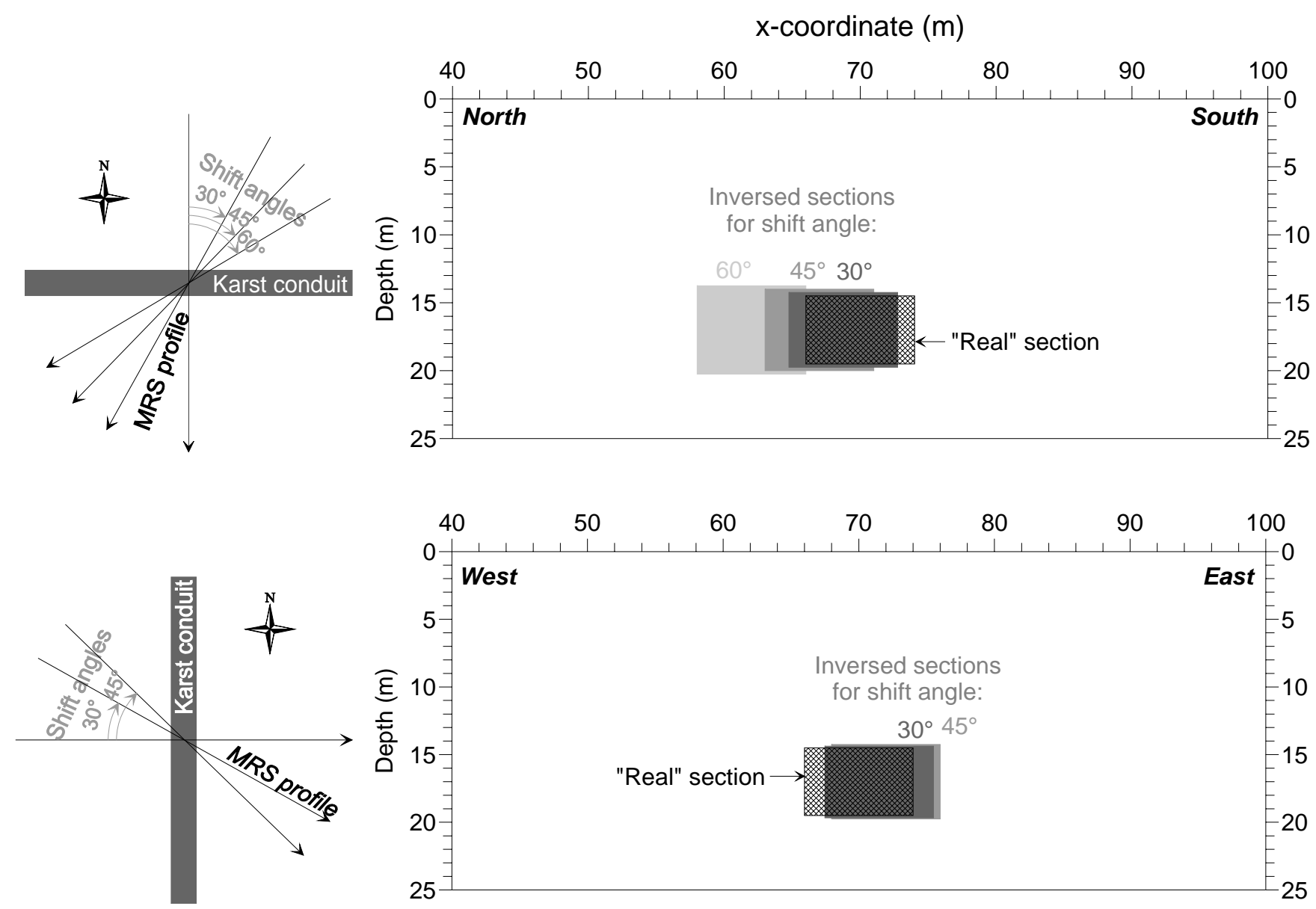

Figure 10: Errors in inversion related to deviation of the MRS profile from perpendicular to the karst conduit's orientation (numerical modelling). 


\section{Figure captions:}

Figure 1: Geographical location and geological setting of the Ouysse karst system (Astruc et al., 1994).

Figure 2: Map of the Poumeyssens karst conduit as measured by cave divers.

Figure 3: Electrical resistivity cross-section in the Poumeyssens area.

Figure 4: MRS signatures of a karst aquifer.

Figure 5: MRS signal and noise recorded using a single loop (left panel) versus a measuring loop in conjunction with a compensation loop (right panel).

Figure 6: MRS amplitude cross-section in the Poumeyssens test site.

Figure 7: Example of soundings taken near to (left panel) and far away (right panel) from the karst cavity location.

Figure 8: Influence of the karst conduit's shape on the MRS signal.

Figure 9: 2D Inversion. A: measured (plus signs) and theoretical signals along the MRS profile - B: RMS as a function of the cavity location and cross-section - C: Result of MRS inversion compared to the section drawn by speleologists.

Figure 10: Errors in inversion related to deviation of the MRS profile from perpendicular to the karst conduit's orientation (numerical modelling). 